\title{
CARDIOVASCULAR RISK FACTORS IN WHITE COLLAR WORKERS UNDER SHIFT WORK
}

\author{
K. Vangelova \\ National Center of Public Health and Analyses - Sofia, Bulgaria
}

\begin{abstract}
Shift work is associated with circadian disruption, disturbs sleep and social life, and modifies disease risk factors, and thus can potentially contribute to various chronic diseases including cardiovascular diseases. The aim of the study was to follow cardiovascular risk in white collar workers under shift work. Cardiovascular risk was studied in sound-engineering staff in sound-recording production. The study encompassed 168 employees (46\% males and $54 \%$ females) working under shift work of age $48.04 \pm 8.8$ years and length of service $21.6 \pm 4.6$ years. Our data show that $31.1 \%$ of the investigated employees were hypertensive, of which $22.6 \%$ had preliminary physician's diagnosis of arterial hypertension, showing comparatively high rates of undiagnosed hypertension, higher in males in comparison to females. The TC and HDL-C were slightly higher with the females, while the triglycerides and TC/HDL-C ratio with the males. High rates of smoking, physical inactivity, overweight and obesity were found with both genders, slightly higher with the females. The preventive approach incorporating regular medical surveillance of shift workers and health promotion covering both life style factors and shift work organization is needed for tackling CVD in shift workers for better cardiovascular health.
\end{abstract}

Key words: arterial hypertension, dyslipidemia, shift work, long-term effects, gender

Corresponding author: K. Vangelova, 15 Acad. Ivan Geshov Blvd, 1431 Sofia, Bulgaria, e-mail:k.vangelova@nepha.goverment.bg

\section{INTRODUCTION}

T he prevalence of shift work is increasing and the shift schedules with night work are estimated to range roughly between 15 and $20 \%$ across the European Union (EU). Shift work is associated with circadian disruption, disturbs sleep and social life, and modifies disease risk factors $[1,2)$. Thus, shift work can potentially contribute to various chronic diseases including cardiovascular diseases (CVDs) [3, 4], a leading cause of death worldwide [5].

Several studies have investigated the association between shift work and CVDs. A meta-analysis [6] confirms a modest association between shift work and myocardial infarction, describing a risk ratio of
1.23 [95\% confidence interval (CI) 1.15-1.31]. Night shift workers have been found to face the highest risk (risk ratio $1.41,95 \% \mathrm{Cl} 1.13-1.76)$. Shift work was not, however, associated with increased rates of mortality. The association of shift work and hypertension is still under debate [7]. Some studies prove an association with the onset and progression of hypertension [8, 9]. Among women who worked as registered nurses, longer duration of rotating night shift work was associated with a statistically significant but small absolute increase in Coronary Heart Disease (CHD) risk [10].

Shift work is related to more unhealthy living habits, especially increased smoking and increased risk of weight gain and obesity, but also high triglyceride 
levels and low HDL-C [11, 12, 13]. No differences between the genders in terms of chronobiological adjustment are found, but the data on cardiovascular risk are inconclusive.

The aim of the study was to follow cardiovascular risk in white collar workers under shift work.

\section{MATERIAL AND METHODS}

Cardiovascular risk was studied in sound-engineering staff in sound-recording production. The study encompassed 168 employees (46\% males and 54\% females) of age $48.04 \pm 8.8$ years and length of service $21.6 \pm 4.6$ years $(19.3 \pm 10.5$ at that particular work place), with no significant differences in terms of age and length of service between the gender groups. The study was approved by the ethical committee of National Center of Public Health and Analyses. The investigated subjects had signed an informed consent.

The work of the sound-engineering staff in sound-recording production is mainly mental, with high job demands, operating with technical equipment, the work posture is monotonous sitting, and work organization includes shift work. The shiftwork schedules of $40.1 \%$ of the male employees and $46.1 \%$ of the females included night shifts, and the shift system was fast rotating, including early morning shifts, day, afternoon and night shifts, while the rest of the studied employees worked rotating morning and afternoon shifts. The duration of the shifts in both groups was 8 hours, and the employees with night work had 5 to 6 night shifts per month.

The cardiovascular risk was assessed on the base of arterial pressure, lipid profile, body mass index (BMI), waist circumference, smoking habits, family history for cardiovascular diseases, etc. The arterial pressure was measured with $\mathrm{Hg}$ sphygmomanometers two times in a period of three months. The hypertension was defined using the JNC VI [14], as well as preliminary physician's diagnosis of arterial hypertension. Weight, height and circumferences at the narrowest part of the waist were recorded, and the BMI was calculated as weight in kilograms divided by height in meters squared. For normal weight $\mathrm{BMl}<25$ was accepted, BMl of 25-30 for overweight and BMI of $30-35$, or $>35$ as obesity.

Blood for analysis was obtained after an overnight fast. The lipid profile included the following indices: total cholesterol (TC), high density lipoprotein cholesterol (HDL-C), low density lipoprotein cholesterol (LDL-C), triglycerides and TC/HDL-C ratio. The assessment of the lipid indices was performed with enzymatic tests. The HDL was separated by precipitation of LDL and VLDL and the cholesterol was assayed in the HDL fraction. The LDL-C was calculated using the formula of Friedewald for triglycerides $<4.3$ $\mathrm{mmol} / \mathrm{l}$. The ratio TC/HDL-C was calculated, too.

A questionnaire on behavioral variables as smoking status, cigarettes smoked per day and duration of smoking, healthy nutrition, consummation of fat foods, alcohol consumption per week, physical activity (practicing some sport and waking during the free time), etc., was filled by the participants. Also questions for weight gain during the last 5 and 20 years were included and the percent of weight gain was calculated.

The data were analyzed using one-way ANOVA, correlation analysis, $\chi^{2}$ and odds ratio of SPSS software. In regression models age, length of service, night work, behavioral variables, family history of arterial hypertension before the age of 60 years, family history of $\mathrm{Ml}$ and cerebral vascular diseases as well as metabolic disorders, parity (nulliparous, 1,2 , or $\geq 3$ children), menopausal status (premenopausal or postmenopausal), hormone therapy (premenopausal, ever, or never) were included.

\section{RESULTS}

Our data show that $31.1 \%$ of the investigated employees were hypertensive, of which $22.6 \%$ had preliminary physician's diagnosis of arterial hypertension, showing comparatively high rates of undiagnosed hypertension (Figure 1), higher in males in comparison to females. The rates of hypertension were also slightly higher in the male employee. With $22.9 \%$ of the investigated the measured systolic blood pressure was $>140 \mathrm{~mm} \mathrm{Hg}$, and with $26.2 \%$ - the diastolic blood pressure $>90 \mathrm{~mm} \mathrm{Hg}$.

The data of the measured blood pressure, anthropometric and metabolic variables in the studied group by gender are presented on Table 1. It can be seen that the male employees had significantly higher systolic blood pressure, as well as slightly higher diastolic blood pressure and BMI. It can be seen that the mean $\mathrm{BMI}$ in both genders exceeded the limit for normal weight. $42.6 \%$ of the investigated had overweight, and $16.4 \% \mathrm{BMI}>30$, indicating obesity. The waist mean values for both genders were high. The TC and HDL-C were slightly higher with the females, while the triglycerides and TC/HDL-C ratio with the males.

Not typically the rate of smoking was slightly higher with the females (38.5\% vs. $22.8 \%$ in the male group). The rate of ex-smokers in the female group was about $7.7 \%$. There were no significant differences in the self reported degree of smoking between the genders (38.0\% of the female employees smoked $5-10$ cigarettes/day, $57.1 \%$ smoked $10-20$ cigarettes/day and $4.9 \%$ more than 20 cigarettes/day while in the male group $39.1 \%$ smoked $5-10$ cigarettes/day, $47.8 \%$ 
smoked $10-20$ cigarettes/day and $13 \%$ more than 20 cigarettes/day). $60.6 \%$ of the males smoked for more than 20 years vs. $57.1 \%$ of the females. The proportion of self reported drinkers was significantly higher in the male group, mainly once to two times per week with moderate number of beverages per week. The self reported nutrition habits showed that the greater part of the investigated declared that have healthy diet and not to consume fatty foods, with higher rates in the females, but the self-reported data showed increase in body weight of more than $10 \%$ during the last 5 years in $18.2 \%$ of the males and $34.2 \%$ of the females $\left(\chi^{2}=\right.$ $3.526, p=0.046)$ and considering 20 year period with $27.3 \%$ in the males and $44.7 \%$ of the females $\left(\chi^{2}=\right.$ $3.595, p=0.043)$. The increase in body weight is related to low physical activity in both genders, especially the females, only $23.0 \%$ practiced some sport vs. $40 \%$ of the males. $65 \%$ of the females and $78.6 \%$ of the males walked once to three times weekly, while $35 \%$ of the investigated females and $21.4 \%$ of the males even had no physical activity of walking.
Accumulation of four or more cardiovascular risk factors was found in great part of the investigated. Very high cardiovascular risk (40\% probability for vessel incident in the next 10 years) was found in $9 \%$ of the male employees and $3.3 \%$ of the female ones. High cardiovascular risk (20-40\% probability for vessel incident in the next 10 years) was assessed in $51.5 \%$ of the male shift workers and $38.5 \%$ of the female shift workers.

In the stepwise regression model the BMI, alcohol consumption and the age were significantly related to the SBP (Table 2). The predictors accounted for $62.60 \%$ of the SBP. Our data showed that $44.7 \%$ of the DBP was associated with the BMI in highly significant model. The TC was predicted by the age, weight gain more than $10 \%$ in the last five years and gender. The night work did not meet the criteria for entering the regression model for TC, but was within a trend ( $b$ adjusted $=.244$, $\mathrm{t}=1.806, \mathrm{p}=0.087$ ). The LDL-C was described by the age, weight gain $>10 \%$ during the last 5 years and gender in highly significant model. The variables explained $33.8 \%$ of the the common variance of LDL-C.

Table 1. The blood pressure, anthropometric and metabolic variables in white collar workers under shift work by gender

\begin{tabular}{|l|c|c|}
\hline \multicolumn{1}{|c|}{ Indices/Groups } & Males & Females \\
\hline SBP $(\mathrm{mm} \mathrm{Hg})$ & $127.2 \pm 16.2$ & $120.5 \pm 20.7^{*}$ \\
\hline DBP $(\mathrm{mm} \mathrm{Hg})$ & $83.7 \pm 9.1$ & $81.0 \pm 11.2$ \\
\hline BMl $\left(\mathrm{kg} / \mathrm{m}^{2}\right)$ & $25.6 \pm 4.6$ & $24.8 \pm 3.7$ \\
\hline Waist $(\mathrm{cm})$ & $96.3 \pm 17.2$ & $85.4 \pm 14.1^{* * *}$ \\
\hline TC $(\mathrm{mmol} / \mathrm{l})$ & $5.11 \pm 0.94$ & $5.50 \pm 0.88^{*}$ \\
\hline $\mathrm{HDL}-\mathrm{C}(\mathrm{mmol} / \mathrm{l})$ & $1.19 \pm 0.23$ & $1.37 \pm 0.30^{* *}$ \\
\hline LDL-C $(\mathrm{mmol} / \mathrm{l})$ & $3.42 \pm 1.12$ & $3.67 \pm 0.91$ \\
\hline Triglycerides $(\mathrm{mmol} / \mathrm{l})$ & $1.83 \pm 1.51$ & $1.45 \pm 0.79^{* *}$ \\
\hline TC/HDL-C ratio & $4.55 \pm 1.00$ & $4.29 \pm 1.02$ \\
\hline
\end{tabular}

${ }^{*} \mathrm{p}<0.05 ; \quad{ }^{* *} \mathrm{p}<0.01 ; \quad{ }^{* * *} \mathrm{p}<0.001$

Table 2. Stepwise multiple regression analysis for cardiovascular risk factors as independent variables

\begin{tabular}{|c|c|c|c|c|}
\hline \multicolumn{2}{|r|}{ Variables } & \multirow[t]{2}{*}{$\beta$} & \multirow[t]{2}{*}{$\mathrm{t}$} & \multirow[t]{2}{*}{ p } \\
\hline Dependent & Predictor & & & \\
\hline 1. SBP & $\begin{array}{l}\text { BMl } \\
\text { Alcohol consumption } \\
\text { Age }\end{array}$ & $\begin{array}{l}.723 \\
.466 \\
.338\end{array}$ & $\begin{array}{l}6.358 \\
4.813 \\
2.873\end{array}$ & $\begin{array}{c}0.000 \\
0.000 \\
0.01\end{array}$ \\
\hline \multicolumn{5}{|c|}{$r^{2}$ for the model $=62.60 \%, F=35.155, p=0.000$} \\
\hline 2. DBP & BMI & .733 & 7.813 & 0.000 \\
\hline \multicolumn{5}{|c|}{$r^{2}$ for the model $=51.40 \%, F=23.160, p=0.000$} \\
\hline \multirow[t]{3}{*}{ 3.TC } & Age & .795 & 5.903 & 0.000 \\
\hline & Weight gain $>10 \%$ during the last 5 years & .583 & 4.249 & 0.000 \\
\hline & Gender & .311 & 2.438 & 0.024 \\
\hline \multicolumn{5}{|c|}{$r^{2}$ for the model $=64.30 \%, F=14.805, p=0.000$} \\
\hline \multirow[t]{2}{*}{ 4. LDL-C } & Age & .710 & 3.903 & 0.001 \\
\hline & Weight gain $>10 \%$ during the last 5 years & .503 & 2.768 & 0.002 \\
\hline \multicolumn{2}{|c|}{$r^{2}$ for the model $=33.80 \%, F=8.293, p=0.002$} & & & \\
\hline
\end{tabular}




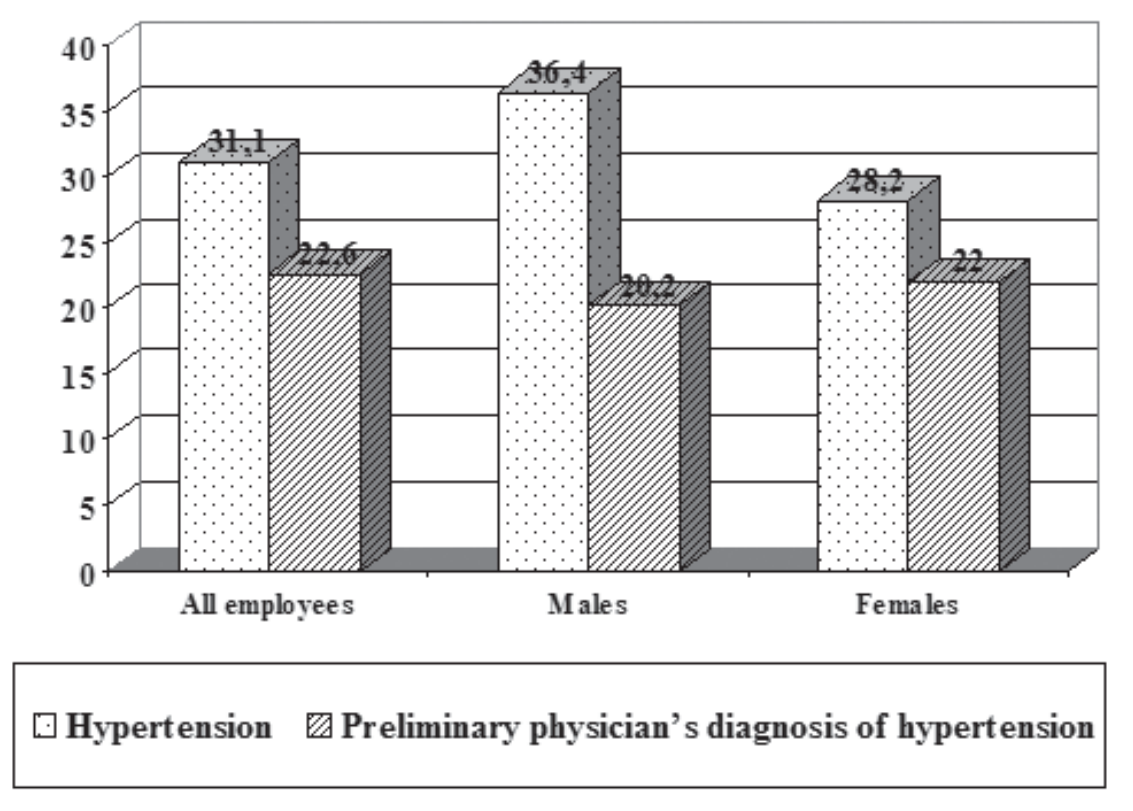

Fig. 1. The rate of employees with hypertension and preliminary physician's diagnosis of hypertension

\section{DISCUSSION}

Our data showed high rates of hypertension in both genders; $36.4 \%$ with the males and $28.20 \%$ with the female employees. It is well known that the high blood pressure (BP) is a major risk factor for CVD [5] and it is estimated to account for $54 \%$ of all strokes and $47 \%$ of all ischemic heart disease events globally [15].

Of concern is the deal of employees with undiagnosed hypertension. With $22.9 \%$ of the investigated the measured systolic blood pressure was $>140 \mathrm{~mm}$ $\mathrm{Hg}$, and with $26.2 \%$ - the diastolic blood pressure > $90 \mathrm{~mm} \mathrm{Hg}$. The risk of cardiovascular mortality grows linearly with BP from $115 / 75 \mathrm{~mm} \mathrm{Hg}$ among adults aged 40-69 years-old with no CVD. At the population level, even a mean systolic BP that was $2 \mathrm{~mm} \mathrm{Hg}$ lower would lead to a reduction in middle-age mortality from coronary heart disease and stroke of approximately $7 \%$ and $10 \%$, respectively $[16,17]$. Our data indicate slightly higher rates of undiagnosed hypertension with the male employees, but the gender differences did not reach significance.

The mean values of TC and LDL-C were high in both genders, higher with the females. The HDL-C was slightly higher with the females, too, while the triglycerides in the males. There are data showing that the impact of stress is greater on arterial pressure in men and on indices associated with insulin resistance, as lipid profile indices, in females [18]. The TC and LDL$C$ were related to the age and weight gain more than $10 \%$ in the last 5 years, the TC also by the gender.
Besides the self-ratings for having healthy diet and not consuming fat foods, $42.6 \%$ of the investigated had overweight, and $16.4 \% \mathrm{BMI}>30$, indicating obesity. In some extent it is related to low physical activity in both genders, especially the females, where only $23.0 \%$ practiced some sport vs. $40 \%$ of the males, and $35 \%$ of the females even had no physical activity of walking and $21.4 \%$ of the males. The weight gain was significantly higher with the females and predicted by specific length of service and physical activity. The self-rated mode of nutrition does not seem to be involved, which is consistent with earlier studies. Hulsegge et al. [19] showed that regardless of number of night shifts and years of shift work, shift workers had similar diet quality as day workers, but with a higher energy intake, especially those with high frequency of night shifts. This suggests that increased energy intake among shift workers may contribute to shift work-induced adverse health outcomes.

Shift work is related also to higher rates of smoking [11], in our study higher rates of smoking were found with the females in comparison to the males. Both smoking and increased risk of weight gain and obesity are considered as mediating life style factors for shift work, rather than confounding [12]. The studied subjects had the same social class, found to be an important confounder [20] and job task. In a review Harma et al. [12] showed that the life style factors do not seem to explain the increased risk to $\mathrm{CHD}$ in shift workers, but considered a multiplicative effect of shift work and life style factors. The author hypothesises 
that the changes in the life style factors do not explain the increased risk of $\mathrm{CHD}$ and points arguments for multiplicative effect of shift work and adverse life style factors.

A strength of the study is that information on shift and night work was available. The studied employees have been working for long period of time under the same shift work schedules, usually more than 20 years and the shift schedules were regular, including 5 to 6 night shifts per month and similar quantity of early morning, day or afternoon shifts. No employees on permanent night shift work over time were involved. Detailed information on a wide range of potential confounding factors was available, too. But as in all observational studies, even though known life style factors were controlled for, confounding due to unmeasured differences in behaviours or other factors may still exist, which is limitation.

In conclusion high rate of employees under shift work with high and very high cardiovascular risk was found, especially for males and should be taken in consideration. Studying CHD related biomarkers and life style factors might be useful in understanding underlying mechanisms. Among men who worked night shifts, the longer duration of rotating night shift work was more pronouncedly associated with increase in arterial pressure and triglycerides, while in women with a statistically significant increase in LDL-C and overweight. The preventive approach incorporating regular medical surveillance of shift workers, as well as health promotion both towards the life style factors and shift work organization is needed for tackling the epidemic of CVD and better cardiovascular health.

\section{REFERENCES}

1. Puttonen S, Härmä M, Hublin C. Shift work and cardiovascular disease - pathways from circadian stress to morbidity. Scand J Work Environ Health. 2010; 36(2):96-108.

2. Ramin C, Devore EE, Wang W, et al. Night shift work at specific age ranges and chronic disease risk factors. Occup Environ Med 2015; 72(2):100-107.

3. Frost $P$, Kolstad HA, Bonde JP. Shift work and the risk of ischemic heart disease - a systematic review of the epidemiologic evidence. Scand J Work Environ Health. 2009;35(3):163-79.
4. Wang A, Arah OA, Kauhanen J, Krause N. Work schedules and 11-year progression of carotid atherosclerosis in middleaged Finnish men. Am J Ind Med 2015:58(1):1-13.

5. Alwan A; World Health Organization. Global status report on noncommunicable diseases 2010. Geneva: WHO Press; 2011.

6. Vyas MV, Garg AX, lansavichus AV, Costella J, Donner A, Laugsand LE, et al. Shift work and vascular events: systematic review and meta-analysis. BMJ. 2012; 345:e4800.

7. Esquirol Y, Perret B, Ruidavets JB et al. Shift work and cardiovascular risk factors: new knowledge from the past decade. Arch Cardiovasc Dis 2011; 104(12):636-668.

8. de Bacquer D, van Risseghem M, Clays E, et al Rotating shift work and the metabolic syndrome: a prospective study. Int J Epidemiol 2009; 38(3):848-854.

9. Kubo T, Fujino Y, Nakamura T et al. An industry-based cohort study of the association between weight gain and hypertension risk among rotating shift workers. J Occup Environ Med 2013; 55(9):1041-1045.

10. Vetter C, Devore E, Wegrzyn L, et al. Association Between Rotating Night Shift Work and Risk of Coronary Heart Disease Among Women. JAMA. 2016;315(16):1726-1734.

11. Boggild $H$, Knutsson $A$. Shift work, risk factors and cardiovascular disease. Scand J work Environ Health 1999;25:85-99.

12. Harma M. Workhours in relation to work stress, recovery and health. Scand J Work Environ Health 2006; 32 (6):502-514.

13. Lin YC, Hsiao TJ and Chen PC. Shift work aggravates metabolic syndrome development among early-middle-aged males with elevated ALT. World J Gastroenterol 2009; 15: 5654-5661.

14. JNC VI. Classification of blood pressure of adults of age 18 years and older. Arch. Intern. Med. 1997; 157: 2413-2446.

15. Mirzaei M, Truswell AS, Taylor R, Leeder SR. Coronary heart disease epidemics: Not all the same. Heart. 2009; 95(9):740-6.

16. MacMahon S, Peto R, Cutler J, et al. Blood pressure, stroke and coronary heart disease. Lancet. 1990;335:765-74.

17. Lewington S, Clarke R, Qizilbash N, Peto R, Collins R. Agespecific relevance of usual blood pressure to vascular mortality: a meta-analysis of individual data for one million adults in 61 prospective studies. Lancet. 2002 Dec 14;360(9349):1903-13.

18. Chrousos, G.P. The role of stress and the hypothalamic-pituitary-adrenal axis in the pathogenesis of metabolic syndrome: neuroendocrine and target tissue-related causes. Intern. J. Obesity 2000; 24 (Suppl. 2): S50-5.

19. Hulsegge G, Boer JMA, van der Beek AJ, et al. Shift workers have a similar diet quality but higher energy intake than day workers. Scand J Work Environ Health 2016;42(6):459-468,

20. Boggild, H., Suadicani, P., Hein, H.O., Gyntelberg F. Shiftwork, social class, and ischaemic heart disease in middle aged and elderly men; a 22 year follow up in the Copenhagen male study. Occup. Environ. Med. 1999; 56(9): 640-645. 